ЮШКОВ Игорь Валерьевич - старший преподаватель департамента политологии факультета социальных наук и массовых коммуникаций Финансового университета при Правительстве РФ (125993, Россия, г. Москва, ГСП-3, Ленинградский пр-кm, 49; ushkovigor@gmail.com

\title{
РАЗВИТИЕ ЦИФРОВОЙ СИСТЕМЫ КОНТРОЛЯ НАД ОБЩЕСТВОМ В РОССИИ
}

\begin{abstract}
Аннотация. В статье проводится анализ причин появления в России цифровой системы общественного контроля и мониторинга поведения граждан в крупных городах. Автор рассматривает развитие технической составляющей цифрового контроля - рост числа камер видеонаблюдения и внедрение системы распознавания лиц. Особое внимание в статье уделяется практикам развития цифрового мониторинга общественного пространства в Москве как лидере данного направления в России.
\end{abstract}

Ключевые слова: контроль, видеонаблюдение, «умный город», управление, “электронная Москва»

\section{Зарождение системы цифрового контроля общественного пространства}

\section{в Москве}

Систему цифрового контроля над гражданами государства можно разделить на две составные части. Первую часть условно можно назвать физической, а вторую - полностью виртуальной. Обе части предполагают использование современных цифровых технологий. Однако первая часть направлена на контроль физических перемещений человека в пространстве, мониторинг и фиксацию его действий в общественном пространстве, условно говоря, его жизни «на улице». А вторая часть - работа государственных органов в области виртуальной реальности: коррекция информационного потока, мониторинг социальных сетей и других интернет-ресурсов, попытки получить доступ к трафику мессенджеров и т.д. Виртуальная часть деятельности государства по установлению контроля над обществом происходит исключительно в интернет-пространстве [Пырма 2019].

Систему контроля перемещения и поведения граждан в общественном пространстве российские власти начали создавать в Москве. И в настоящее время Москва остается лидером среди российских городов по уровню внедрения цифровых технологий. Остальные регионы, как правило, перенимают опыт Москвы и имеют только небольшие отличия системы общественного контроля. Поэтому целесообразно рассматривать именно столичный опыт.

Система контроля поведения граждан в городском пространстве основывается на двух элементах: 1) комплексе видеонаблюдения, 2) системе распознавания лиц и идентификации личности на базе видео [Юшков 2020: 25]. Исторически первой появилась система видеонаблюдения. Это объясняется логикой развития информационных технологий - по мере развития компьютерных программ.

В нашей стране уличные видеокамеры устанавливались еще в советские годы. Это происходило в рамках повсеместных попыток автоматизации процессов и планирования. Внедрение средств видеонаблюдения предполагалось осуществить для управления потоками автомобильного транспорта в крупных городах СССР. В частности, в начале $1980-$ х гг. во всех советских городах с населением свыше 100 тыс. чел. планировалось установить системы автоматизированного управления дорожным движением (АСУДД). В рамках совершенствования подобных систем необходимо было устанавливать большое число датчиков, чтобы иметь возможность корректировать транспортные потоки. А для обработки получаемых данных и автоматической корректировки работы 
светофоров нужны были ЭВМ. Несмотря на высокую стоимость подобных комплексов, пробные системы были созданы в Москве (система «СТАРТ») и в Алма-Ате (система «Город», разработанная СКБ «Промавтоматика») [Качанов, Попов 2019: 5].

Вторая волна развития систем видеонаблюдения в нашей стране прошла в 1990-х гг. В Москве стали появляться видеокамеры для контроля входа в подъезды, дворовой территории, отдельных улиц и т.д. Причиной распространения видеокамер в Москве стало желание прежде всего богатых граждан повысить безопасность в общественных пространствах. Подобный эволюционный путь не уникален. Германия была мировым лидером по применению систем видеомониторинга. Немецкий инженер Вольтер Брюк по заказу компании Siemens создал систему видеонаблюдения, которая должна была передавать картинку с ракетного полигона в реальном времени. Немецкие военные и ученые таким образом отслеживали неисправности во время запусков. В послевоенный период, в 1960 г., в Ганновере и Мюнхене были установлены видеокамеры, отслеживавшие движение автомобилей и пешеходов на переходах. А в Великобритании впервые стали применять видеокамеры для мониторинга поведения людей на улицах.

Зарубежный и отечественный опыт отличаются тем, что в европейских странах система видеоконтроля дорожного движения развивалась непрерывно. А в нашей стране с начала 1990-х до нулевых годов по причине отсутствия финансирования модернизация системы управления дорожным движением не проводилась. Кроме того, руководство как страны в целом, так и крупных городов, таких как Москва, не считали улучшение в данной области приоритетной задачей. Другое направление - установка камер видеонаблюдения с целью повышения безопасности - уже в 1990-е гг. стало активно развиваться вследствие повышенной криминогенности.

На первом этапе развития системы видеонаблюдения в России происходила установка камер на подъездах жилых домов. При этом видео записывалось на локальный носитель и не передавалось на централизованное хранение. У городских властей даже не было доступа к некоторым частным камерам видеонаблюдения. Но это не являлось проблемой, т.к. у правоохранительных органов не было опыта их использования, а число самих камер было крайне мало. Можно сказать, что государство (на примере Москвы) приходит в сегмент видеонаблюдения только в начале нулевых годов.

\section{Создание централизованной системы цифрового контроля}

В 2001 г. столичные власти закупают около 80 тыс. камер видеонаблюдения и устанавливают их в подъездах жилых домов и на выходе из них. Кроме того, появляются первые попытки использования видеокамер для мониторинга поведения людей в общественных местах. Для этого в Москве в 120 местах массового пребывания граждан были установлены видеокамеры. У такой системы видеонаблюдения не было централизованной системы управления [Мухаметов, Симонов 2021: 20]. Отчасти это объясняется неразвитостью средств передачи информации. Установленные в 2001 г. в Москве камеры передавали данные в районные локальные центры мониторинга (ЛЦМ). Там они записывались на жесткие диски, которые хранились в помещениях данных центров. В самих ЛЦМ работали преимущественно пенсионеры, которые смотрели только за тем, чтобы на мониторах наблюдения была картинка. Также был необходим сотрудник для предоставления доступа работникам правоохранительных органов к архиву видеозаписей.

Но даже правоохранительным органам работать с такой децентрализованной 
системой видеонаблюдения было сложно. Во-первых, качество изображения тех камер было плохое, устройства записывали черно-белую картинку. Неудачное расположение камер позволяло зачастую увидеть на записи только затылок человека, заходившего в подъезд. Во-вторых, сотрудникам милиции в случае необходимости просмотреть видео с камер наблюдения приходилось звонить в один из 125 районных ЛЦМ, узнавать, есть ли записывающее устройство на нужном подъезде или улице. Далее сотрудник правоохранительных органов должен был поехать в нужный ему район и взять там видеозапись с конкретной камеры. Причем из-за отсутствия достаточного финансирования на закупку серверов записи с камер видеонаблюдения хранились непродолжительный период времени (конкретный период даже не регламентировался). Проблема ограниченного периода хранения данных с камер видеонаблюдения сохраняется и сейчас (по официальным данным, запись доступна в течении 5 суток). Естественно, что из-за нежелания куда-то ехать и отсутствия достаточного времени для этого сотрудники милиции неохотно пользовались записями камер видеонаблюдения. С точки зрения главной цели установки оборудования видеоконтроля обеспечения общественной безопасности - система была малоэффективной.

Кроме того, в Москве в начале нулевых годов все затраты на установку видеокамер, прокладку кабелей, услуги монтажа и обслуживания оборудования брал на себя московский бюджет. К началу 2010-х гг. столичное руководство признало программу развития системы видеонаблюдения в городе экономически неэффективной.

В 2011 г. начался новый этап развития системы видеонаблюдения в столице. Фактически именно тогда началось конструирование современной модели мониторинга общественного пространства. Руководство Москвы внедрило два новых фундаментальных элемента, которые позволили получить качественно иную систему видеоконтроля. Во-первых, город отказался от использования собственных уличных камер. Теперь установкой и обслуживанием оборудования должны заниматься частные компании, а город закупает у них изображение. Закупками контента стал заниматься Департамент информационных технологий г. Москвы. Он выставлял определенные требования к качеству видеозаписей: локация камеры, четкость изображения, полнота кадра, непрерывность видеопотока, хранение данных на протяжении 5 суток и т.д. Право на поставку видеоконтента разыгрывалось на конкурсной основе. В случае нарушения параметров видео поставщик штрафовался. Начальник отдела городского видеонаблюдения Департамента информационных технологий Москвы Дмитрий Головин в 2018 г. рассказывал, что в результате перехода на сервисную модель затраты города на получение данных с камер видеонаблюдения снизились на 40\%. Этого результата удалось добиться благодаря конкуренции операторов, в результате которой происходит постоянная модернизация оборудования.

Вторым важным нововведением стала централизация потоков данных. С 22 марта 2011 г. все данные из районных локальных центров стали поступать в Единый центр хранения и обработки данных (ЕЦХД). Теперь для получения данных из системы видеонаблюдения, в т.ч. в режиме реального времени, представители спецслужб, полиции, МЧС и работники других уполномоченных служб не должны никуда ездить. Доступ предоставляется им с их рабочих мест, подключенных к сети Интернет. Работнику предоставляется логин и пароль для доступа к ресурсам ЕЦХД.

\section{Современный этап развития цифрового контроля в Москве}

Во второй половине 2010-х гг. система уличного видеомониторинга существенно изменилась. Если раньше система видеокамер помогала фиксировать 
деятельность людей в общественном пространстве, то во второй половине 2010-х гг. власти захотели использовать ее для контроля и корректировки поведения людей.

В 2011 г. была принята программа «Цифровой город», которая закрепила основные цели информационного развития столицы и обеспечила финансирование преобразований. С 2011 по 2019 г. бюджет программы составил более 545,9 млрд руб.

Реализация программы «Информационный город» должна была повысить общее число камер видеонаблюдения в Москве, подключенных к ЕЦХД, до 145 тыс. в 2016 г. и до 160 тыс. в 2019 г. Однако к началу 2019 г. эти показатели уже были превышены - в Москве насчитывалось 167 тыс. камер, а к концу 2019 г. показатель вырос до 174 тыс. Плановые показатели покрытия видеонаблюдения в подъездах должны были вырасти почти в 2 раза: $36 \%$ в 2011 г., 59\% в 2012 г., 86,3\% в 2018 и $90 \%$ в 2019 г.

Реализация программы позволила подключить к единой системе сбора данных различные государственные учреждения: больницы, поликлиники, школы, вузы, МФЦ и т.д. Таким образом, государство стало получать большой поток данных о гражданах. Всего мэрия и правительство Москвы имеет доступ к 170 информационным системам в соответствии с различными аспектами жизнедеятельности города.

Технологическая база для трансформации системы видеонаблюдения постепенно менялась. Изначально комплекс видеомониторинга в Москве был создан на базе оборудования американской компании Cisco Video Service Manager. Однако в дальнейшем городские власти диверсифицировали поставщиков оборудования и программного обеспечения. Этого потребовало и изменение политической обстановки: после 2014 г. США стали вводить антироссийские санкции, а также появился риск удаленного использования американского оборудования разведками западных стран в своих интересах. С другой стороны, американское оборудование не во всех сегментах является передовым. В 2014 г. российская система видеонаблюдения перешла на российское видеоядро Netris VoD Server. Часть оборудования стала закупаться в Китае.

Изменение при выборе оборудования и программного обеспечения было обусловлено в т.ч. тем, что Москва стала внедрять систему распознавания лиц. Это стало следующим шагом в процессе создания системы контроля общества с помощью новых технологий. Первые две государственные программы («Электронная Москва» и «Цифровой город») позволили создать сеть камер видеонаблюдения и интегрированную централизованную систему сбора данных о гражданах из различных источников.

В 2018 г. московские власти опубликовали стратегию «Умный город - 2030». Этот документ имеет довольно общий вид. Центральной идеей в нем является применение искусственного интеллекта для улучшения жизни в Москве. Естественно, гражданам нововведение преподносится только с позитивной точки зрения: электронная запись к врачам в поликлинике, все документы можно оформить в центре «Мои документы», электронная передача показаний электрических и водяных счетчиков. Вопросы по теме ЖКХ решаются через звонок в единую диспетчерскую, любую жалобу можно направить через систему «Активный гражданин» и т.д. Показательно, что в стратегии «Умный город - 2030» указано, что москвичи сами ждут от города большей персонификации здравоохранения и повсеместного внедрения системы «умный дом».

Таким образом, за последние десятилетия в Москве была создана полноценная система цифрового мониторинга общественного порядка, которая переросла в фундамент для развития различных сервисов и системы «Умный 
город» [Симонов 2020]. Граждане подключаются к совершенствованию данной системы, поэтому функция контроля трансформировалась во всеобъемлющую экосистему взаимодействия государства и общества. Однако центральная задача цифровизации города и страны в целом остается прежней - контролировать общество.

Статья подготовлена по результатам исследований, выполненныхза счет бюджетных средств по государственному заданию Финансовому университету при Правительстве РФ.

\section{Список литературы}

Качанов С.А., Попов А.П. 2019. О месте аппаратно-программного комплекса «безопасный город» в концепции «умный город». - Технологии гражданской безопасности. № 3. С. 4-9.

Мухаметов Д.Р., Симонов К.В. 2021. «Умное государство»: перспективы внедрения цифровых технологий государственного управления в России. - Мир новой экономики. № 3. С. 17-27.

Пырма Р.В. 2019. Влияние цифровых коммуникаций на политическое участие. - Гуманитарные науки. Вестник Финансового университета. № 4. С. 63-69.

Симонов К.В. 2020. Куда приведут технологии? Выбор между цифровой полиархией, цифровым авторитаризмом и цифровой анархией. - Гуманитарные науки. Вестник Финансового университета. № 6. С. 6-11.

Юшков И.В. 2020 Феномен цифрового популизма: истоки и современное состояние. - Обозреватель - Observer. № 10(369). С. 21-31.

\section{DEVELOPMENT OF A DIGITAL SYSTEM OF CONTROL OVER SOCIETY IN RUSSIA}

Abstract. The article analyzes the reasons for the emergence of a digital system of public control and monitoring of citizens' behavior in large cities in Russia. The author considers the development of the technical component of digital control - the growth of the number of video surveillance cameras and the introduction of a facial recognition system. The author pays a special attention to the practices of the development of digital monitoring of public space in Moscow, as the leader of this direction in Russia.

Keywords: control, video surveillance, smart city, management, electronic Moscow 